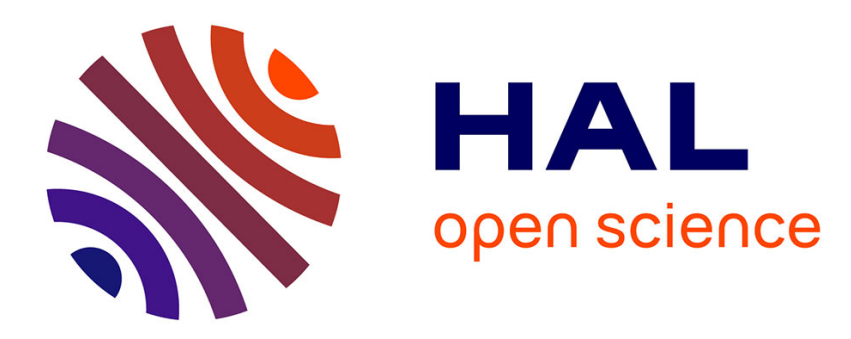

\title{
Temporal clustering of retroreflective marking
}

\author{
M Redondin, N Faul, Laurent Bouillaut, Dimitri Daucher
}

\section{To cite this version:}

M Redondin, N Faul, Laurent Bouillaut, Dimitri Daucher. Temporal clustering of retroreflective marking. ESREL 2017, European Safety and Reliability Conference, Jun 2017, Portoroz, France. 7p. hal-01539102

\section{HAL Id: hal-01539102 \\ https://hal.science/hal-01539102}

Submitted on 14 Jun 2017

HAL is a multi-disciplinary open access archive for the deposit and dissemination of scientific research documents, whether they are published or not. The documents may come from teaching and research institutions in France or abroad, or from public or private research centers.
L'archive ouverte pluridisciplinaire HAL, est destinée au dépôt et à la diffusion de documents scientifiques de niveau recherche, publiés ou non, émanant des établissements d'enseignement et de recherche français ou étrangers, des laboratoires publics ou privés. 


\title{
Temporal clustering of retroreflective marking
}

\author{
M. Redondin, N. Faul \\ Institute VEDECOM, 77 rue des chantiers, F-78000 Versailles, France \\ L. Bouillaut*, D. Daucher** \\ *Université Paris-Est, Grettia (IFSTTAR), F-77455 Marne-la-Vallée, France \\ **Université Paris-Est, Lepsis (IFSTTAR), F-77455 Marne-la-Vallée, France
}

\begin{abstract}
The quality and reliability of road infrastructure and its equipment play a major role in road safety. This is especially true if we are interested by autonomous cars traffic able to read road marking. This kind of vehicles needs an accurate maintenance strategy to guarantee a road with marking perceptible for a human eye or an autonomous car. To simplify the study of a road and because a maintenance campaign is generally applied for a part of the road, a solution based on an Agglomerative Hierarchical Clustering to cluster all markings is chosen. In the case of no follow-up of the maintenance for markings, a maintenance detector will be introduced and described. Finally, with this classification, it is possible to extract all maintenance cycles and identify the different maintenance actions. This approach is a first step to analyze the useful life of marking with a Weibull analysis. Skip center line of the French National Road 4 is considered to illustrate the proposed approach.
\end{abstract}

Keyword : Agglomerative Hierarchical Clustering, retroreflection, marking, maintenance cycle

\section{INTRODUCTION}

The quality and reliability of road infrastructure and its equipment play a major role in road safety. This is especially true if we are interested by autonomous cars traffic. Currently, an autonomous vehicle is guided thanks to a GPS system. Unfortunately, this system isn't enough precise and not reliable (urban canyon, tunnel...). In order to complete the current system, an option consists in fitting the vehicle with a camera able to read markings. This solution needs an accurate maintenance strategy to guarantee a road with marking perceptible for a human eye or an autonomous car.

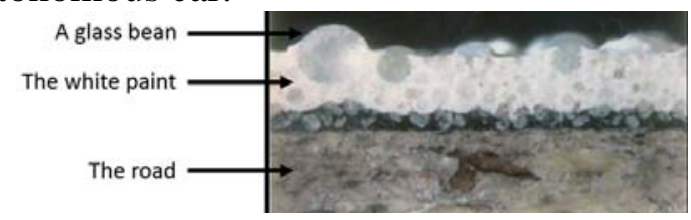

Figure 1. Sectional view of a white water-based paint retroreflective marking.

A retroreflective marking reflects the light from a vehicle on the direction of his driver. The figure 1 presents a white water-based marking. The paint is just laid on the road and glass beans are mixed to the paint. Their beans guarantee the retroreflexion property. In France, this kind of marking is mandatory for all roads located outside urban area (Instruction interministérielle sur la signalisation routière, 1988).

Markings are subjected to degradation over time, mainly due to the traffic, environmental conditions and materials properties of marking and the road. Therefore markings lose paints and glass beans, be-

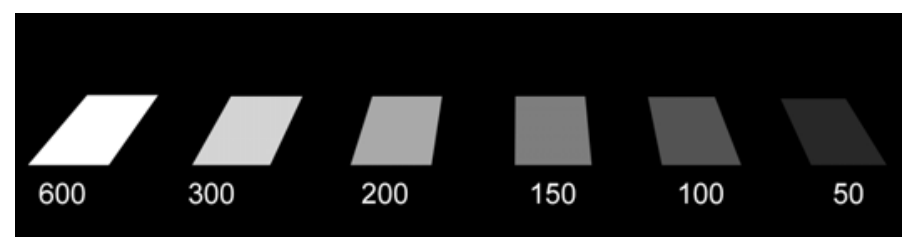

Figure 2. Representation of a white marking according to it retroreflexion level $\left(\mathrm{mcd} / \mathrm{m}^{2} / \mathrm{lx}\right)$

comes grey... The retroreflectivition level of a marking is measured by millicandela by square meter and by luminance $\left(\mathrm{mcd} / \mathrm{m}^{2} / \mathrm{lx}\right)$. According to AFNOR rules (AFNOR, 2009 ), a minimum threshold of $150 \mathrm{mcd} / \mathrm{m}^{2} / \mathrm{lx}$ has to be respected by all constructors. The figure 2 represents a markings according to it retroreflexion level. With a high level of retroreflexion $\quad\left(>150 \mathrm{mcd} / \mathrm{m}^{2} / \mathrm{lx}\right)$, the marking is white and seeable. But with a retroreflexion level less to $150 \mathrm{mcd} / \mathrm{m}^{2} / \mathrm{lx}$, it become grey and not enough seeable. The retroreflectivition level of a marking is a good indicator to analyze its degradation.

If a marking loses its retroreflectivity property then its replacement is the only possible maintenance action. Installment of markings in outside urban area is made by an adapted truck (Fig. 3a). For a water-based paint marking installation, experts could use the "sandwich" technique (Fig. 3b). The truck transport paints, glass beans and anti-skid products. 
A first valve paints the road, a second puts glass beans on the marking and a last adds the anti-skid products. The quantity of each component depends to the constructor.

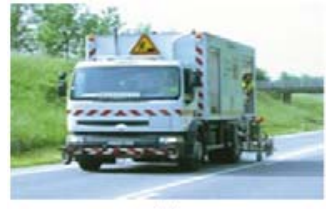

(a)

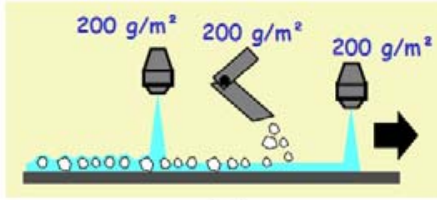

(b)
Figure 3. (a) A truck able to lay marking, (b) The "sandwich" lay technique.

The retroreflexion level of a marking is evaluated by a retroreflectometer. In this paper, an Ecodyn from Vectra is considered. This retroreflectometer is fitted to a car side and reliable to a laptop inside the car (Fig. 4a). This instrument measuring gives off a white light to markings and measuring the quantity of light retroreflected (Fig. 4b). Ecodyn measuring also thanks to some sensors the daytime and the nighttime contrast. The laptop creates automatically a data base and associate each measure to a point of reference thanks to an associated software (Fig. 4c).

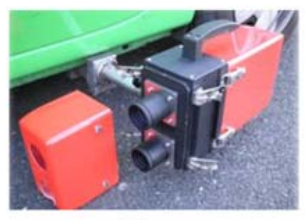

(a)

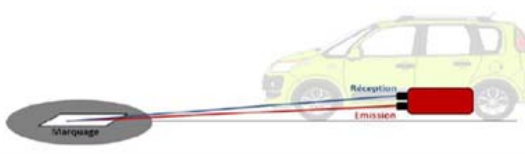

(b)

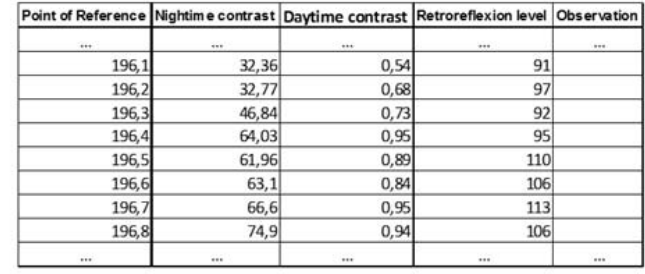

(c)

Figure 4. Presentation of an Ecodyn: (a) An Ecodyn fitting to a car, (b) The measuring process, (c) Example of a data base (Vectra France, 2017).

The current configuration could analyze the retroreflection level each $40 \mathrm{~cm}$ but gives only an average on $100 \mathrm{~m}$. In fact, each measure represents an average of three or four markings. To simplify, a measure is analyzed like one marking.

To evaluate the economic impact of replacing a marking, a performance-based approach of the maintenance is chosen. Specifically in markings case, a preliminary work is: how each marking was installed? What kind of marking was chosen? What is the current maintenance strategy? Are there some strategic area?

The major part of the literature supposes some conditions. For example: a test desk is considered (Bahar, et al., 2006) (Zhang \& Wu, 2006), the study starts 6 months after the lay date (Karwa \& Donnell, 2011), the kind of marking is known (Sarasua, et al., 2003) or the road is monthly inspected (Sathyanarayanan, et al., 2008). In addition, followup of the maintenance campaigns for markings and regular inspection campaigns are complete. In the reality, the follow-up may incomplete and markings could be inspected only once a year. As a result, incomplete data on the monitoring of marking retroflectivity exists and installment dates of markings must be estimated.

Our approach is similar to (Migletz, et al., 2001) : the study is based on a specific road regularly inspected. To simplify the road and because a maintenance campaign is generally applied for a part of its, a solution based on an Agglomerative Hierarchical Clustering (Tufféry, 2011) to cluster all marking according to the geographic position and the retroreflection evolution is chosen. The study of the road is reduced to some cluster represented by an average profile. To estimate lay date of marking, a maintenance detector based on the previous clustering and accorded to AFNOR rules (AFNOR, 2009 ) is proposed.

Our hypothesis is that each cluster represents a specific part of the road. This part admits its own retroreflection evolution and past maintenance actions can be deduce.

Skip center line of the French National Road 4 (NR4) is considered to illustrate the proposed approach. This road joins Paris and Strasbourg. Since 2007, the part between Courgivaux and Perthes $(\sim 104 \mathrm{~km})$ is managed by the DIR Est with two management teams (Direction Interdépartementale des Routes de l'Est, 2008). In order to evaluate the state of markings, one inspection a year is organized in collaboration with the CEREMA with an Ecodyn where each measure is located by a reference point. Unfortunately, it doesn't exist any follow-up of the maintenance campaigns for markings.

The following sections present the Agglomerative Hierarchical Clustering and the maintenance detector both applied on skip center line of the NR4. 


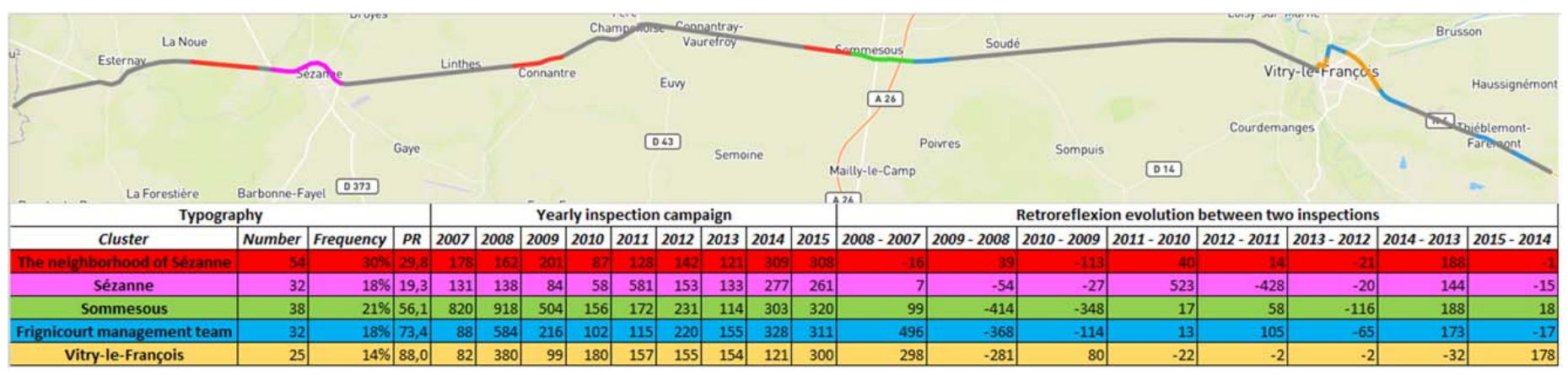

Figure 5. AHC of NR4 skip center lines and average profile of each cluster.

\section{THE AGGLOMERATIVE HIERARCHICAL CLUSTERING}

\subsection{Definition and properties of the AHC}

The Agglomerative Hierarchical Clustering (Tufféry, 2011) (AHC) consists to produce sequences of partitions of increasing heterogeneity between partition into n clusters where each object is isolated and partition into one cluster which includes all the objects. A marking is defined by its geographic Point of Reference (PR), inspections measures and retroreflexion evolution between two inspections. The general form of the AHC is the following:

1. Each marking is a cluster.

2. The distance between clusters are calculated.

3. The two closer clusters are merged into one.

4. Start again at step 2 until there is only one cluster, which contains all marking.

The second step introduces a distance between two clusters. In the case of two markings, the Euclidian distance $\mathrm{d}$ is considered. Else, the Ward distance (1) is chosen where X, Y are both clusters; $\mathrm{x}, \mathrm{y}$ their average profiles; $n_{X}, n_{Y}$ their numbers:

$$
d_{w}(X, Y)=\frac{d(x, y)}{\frac{1}{n_{X}}-\frac{1}{n_{Y}}}
$$

The choice of the number of cluster is based on the semi-partial $\mathrm{R}^{2}$ criterion. This criterion calculates the loss of between-class inertial. This loss must be as small as possible.

The statistical software $\mathrm{R}$ could represent the clustering process and the semi-partial $\mathrm{R}^{2}$ in a same dendrogram.

\subsection{Application to the National Road 4}

The DIR Est organizes in collaboration with the CEREMA the annual inspection campaign in late September. This period presents some advantages: main work sites are theoretically over, there isn't specific work like the maintenance of the flora and retroreflexion measures are registered before the first snowfalls. The retroflectometer used is an Ecodyn from Vectra.

In this paper the monitoring between 2007 and 2015 of skip center line is restricted to markings inspected each time. 181 measures can be analyzed. It represents approximately $17 \%$ of the road. Each marking is defined by one point of reference, nine inspection measures and eight retroreflection evolution between two inspections. In fact, a marking can be analyzed like a point in the space vector $R^{18}$.

The AHC proposes five clusters. According to the restricted data, Figure 5 shows all clusters directly on a map and presents all average profiles. A color code is chosen to represent the associate dendrogram (Fig 6). The semi-partial $\mathrm{R}^{2}$ is small: $18 \%$.

1. The first cluster (red) represents the neighborhood of Sézanne.

2. The second cluster (purple) represents the city of Sézanne.

3. The third cluster (green) represents the city of Sommesous.

4. The fourth cluster (blue) represents the Frignicourt maintenance team area.

5. The fifth cluster (orange) represents the city of Vitry-le-François.

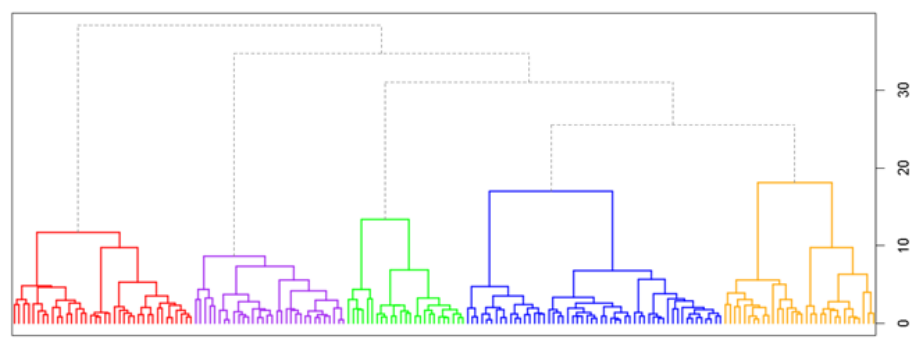

Figure 6. Dendrogram associated to the AHC of NR4 skip center lines.

Each cluster matches with a city area met by the road or one of two management teams. The first 
three clusters represent the Sézanne management team area and the last clusters represent the Frignicourt management team area. From now on all clusters are named by its geographic area.

Cities of Sézanne, Sommesous and Vitry-leFrançois present a specific road network. Figure 5 shows that Sézanne merges two departmental roads (D373a and D373b) in addition to the NR4, Sommesous is a highway (A26) exit and Vitry-leFrançois merges two national road (NR44) and guides the traffic to Strasbourg, Paris or Northern France. These situations could create a local stronger traffic which could damage markings more quickly. A local maintenance strategy is required in this situation.

Admissible alternatives clustering propose three or four clusters. These versions considered one general maintenance strategy with one or two specific area (Sézanne and Sommesous) and a bigger semipartial $\mathrm{R}^{2}$. In the absence of maintenance historic, the maintenance detector and the current road manager strategy to the clustering is favored.

\subsection{Mathematical formalism}

An adapted mathematical formalism both to the clustering and the current studied is applied from now. Let supposes $n$ markings and $N_{C}$ clusters.

Each marking is defined by $i=1, \ldots, n$.

Clusters are noted by $C_{j}$ where $j=1, \ldots, N_{C}$. The cardinal of a cluster $C_{j}$ correspond to the number of marking classified in $C_{j}$ and is noted by $\# C_{j}$. A marking took from $C_{j}$ is noted $m_{k}$ where $k=$ $1, \ldots, \# C_{j}$.

According to the current literature, the Retroreflexion Level is noted $R L$. The retroreflexion level of a marking $i$ at the inspection $t$ is $R L_{t}^{i}$. The retroreflexion evolution between two inspections $t$ and $t-1$ is defined by (2).

$$
\Delta R L_{t}^{i}=R L_{t}^{i}-R L_{t-1}^{i}
$$

The retroreflexion level of a cluster $C_{j}$ at the inspection $t$ and the evolution beteween two inspections corresponding respectively to the average retroreflexion level (3) at the same inspection and the average evolution (4) in the same period.

$$
\begin{aligned}
& R L_{t}^{C_{j}}=\frac{1}{\# C_{j}} \sum_{m_{k} \in C_{j}} R L_{t}^{m_{k}} \\
& \Delta R L_{t}^{C_{j}}=\frac{1}{\# C_{j}} \sum_{m_{k} \in C_{j}} \Delta R L_{t}^{m_{k}} \\
& e_{t}^{C_{j}}=\Delta R L_{t}^{C_{j}}-\sqrt{\frac{1}{\# C_{j}} \sum_{m_{k} \in C_{j}}\left(\Delta R L_{t}^{m_{k}}-\Delta R L_{t}^{C_{j}}\right)^{2}}
\end{aligned}
$$

A last indicator is the average lowest increasing for a cluster $C_{j}$ at the inspection $t$ (5). The right member is the standard error associated to $\Delta R L_{t} C_{j}$.

\section{THE MAINTENANCE DETECTOR}

\subsection{Construction of the detector}

Two hypotheses are supposed. All inspections are realized after maintenance campaigns and indicated to managers which marking must be replaced during the next months and only one specific marking product (thermoplastic, water-based paint...) is laid.

A minimum threshold of $150 \mathrm{mcd} / \mathrm{m}^{2} / \mathrm{lx}$ for a no defective marking is chosen. For a marking ter $C_{j}$, four maintenance actions are identified.

1. A Full Maintenance (FM) consists to replace all markings.

2. A Partial Maintenance (PM) consists to replace only a part ( $70-90 \%)$ of markings.

3. A punctual Maintenance (pM) consists to replace only a few marking ( 1-30\%).

4. Nothing $(\varnothing)$ if no maintenance.

Let $a=\{\mathrm{FM}, \mathrm{PM}, \mathrm{pM}, \emptyset\}$ is the set of maintenance action possible. The action into the marking $i$ during the year $t$ is noted $a_{i}^{t}$.Each year and for all cluster, the number of marking replaced is counted. The detector is based on two steps: the marking step and the clusters step.

The marking step is represented by figure 7 .

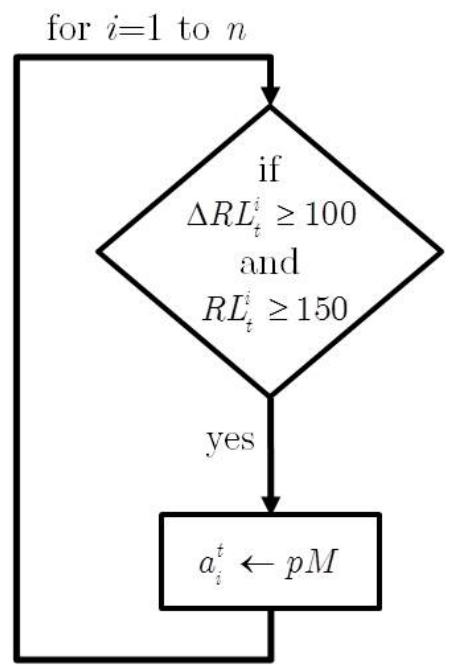

Figure 7. The markings step of the maintenance detector.

Let consider a given marking $i$ at inspection $t$. If $\Delta R L_{t}^{i}>100$ and $R L_{t}^{i}>150$ then $i$ is punctually maintained. An increasing (at least) $100 \mathrm{mcd} / \mathrm{m}^{2} / \mathrm{lx}$ could detect a marking replaced but also stressed during the period between the lay date and the first inspection.

The clusters step is represented by figure 8 . Let consider a given marking cluster $C_{j}$ at inspection $t$.

1. If $\Delta R L_{t}^{C_{j}} \geq 150$ then the cluster is fully maintained. This step detects all clear

2. Else if $\Delta R L_{t}^{C_{j}}<0$ or $R L_{t}^{C_{j}}<150$ then the cluster isn't maintained. The step joins a maintenance campaign objectives: the cluster 
have of a bigger retroreflexion level and isn't defective.

3. Else if $e_{t}^{\dot{C} j}>0$ them the cluster is also fully maintained but markings are stressed.

4. Else $C_{j}$ is subset to markings as

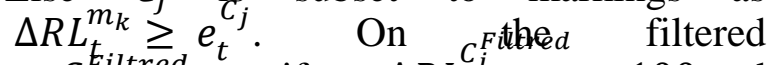

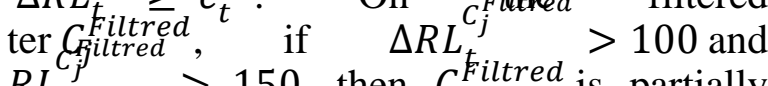
$R L_{t}^{C_{j}}>150$ then $C_{j}^{\text {Filtred }}$ is partially maintained.

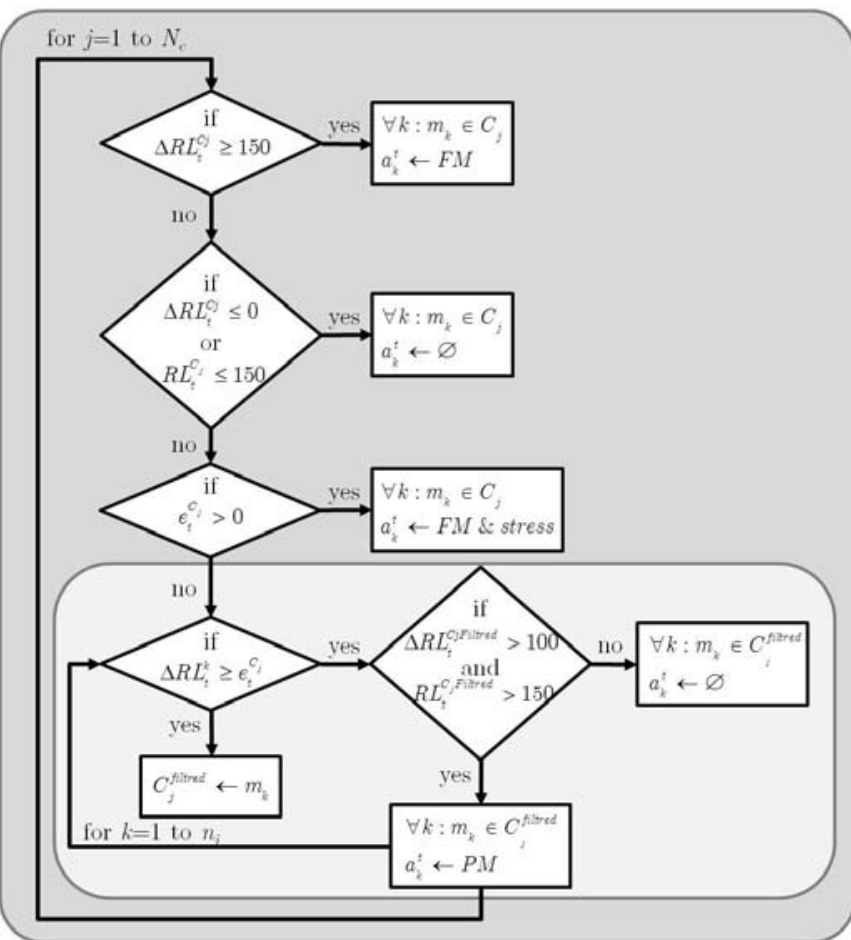

Figure 8. The clusters step of the maintenance detector.

\subsection{Application to the National Road 4}

According both to the AFNOR rules (AFNOR, 2009 ) and DIR Est directives (Direction Interdépartementale des Routes de l'Est, 2008), a minimum threshold of $150 \mathrm{mcd} / \mathrm{m}^{2} / \mathrm{lx}$ for a no defective marking is chosen. In 2008, the DIR Est chooses a water-based paint marking for the skip center line (Direction Interdépartementale des Routes de l'Est, 2008).

The table 1 indicates the maintenance action history of each clusters. Average profiles (Fig. 1) specified if a cluster was over maintained (a marking no defective replaced) or had an under maintained period (a defective marking not replaced). To simplify analysis, punctual maintenances are excluded.

1. The neighborhood of Sézanne is maintained in 2014. This cluster had an under maintained period between 2010 and 2013.

2. Sézanne is maintained in 2010 and 2014. This cluster had an under maintained period between 2007 and 2010.

3. Sommesous is maintained in 2008, 2012 and 2014. This cluster was over maintained in 2008.
4. The Frignicourt maintenance team is maintained in 2008, 2012 and 2014. This cluster had an under maintained period between 2010 and 2011.

5. Vitry-le-François is maintained in 2008 and 2015.

\begin{tabular}{|c|c|c|c|c|c|c|c|c|c|}
\hline Cluster & Maintenance & 2008 & 2009 & 2010 & 2011 & 2012 & 2013 & 2014 & 2015 \\
\hline \multirow{5}{*}{$\begin{array}{c}\text { The } \\
\text { neiborhood } \\
\text { of Sézanne }\end{array}$} & Full & & & & & & & $100 \%$ & \\
\hline & Stress & & & & & & & & \\
\hline & Partial & & & & & & & & \\
\hline & Punctual & & $31 \%$ & & $7 \%$ & & & & $4 \%$ \\
\hline & Nothing & $100 \%$ & $69 \%$ & $100 \%$ & $93 \%$ & $100 \%$ & $100 \%$ & & $96 \%$ \\
\hline \multirow{5}{*}{ Sézanne } & Full & & & & $100 \%$ & & & & \\
\hline & Stress & & & & & & & $100 \%$ & \\
\hline & Partial & & & & & & & & \\
\hline & Punctual & & & & & & & & $3 \%$ \\
\hline & Nothing & $100 \%$ & $100 \%$ & $100 \%$ & & $100 \%$ & $100 \%$ & & $97 \%$ \\
\hline \multirow{5}{*}{ Sommesous } & Full & & & & & & & $100 \%$ & \\
\hline & Stress & & & & & $100 \%$ & & & \\
\hline & Partial & $79 \%$ & & & & & & & \\
\hline & Punctual & & & & & & & & $8 \%$ \\
\hline & Nothing & $21 \%$ & $100 \%$ & $100 \%$ & $100 \%$ & & $100 \%$ & & $92 \%$ \\
\hline \multirow{5}{*}{$\begin{array}{c}\text { Frignicourt } \\
\text { management } \\
\text { team }\end{array}$} & Full & $100 \%$ & & & & & & $100 \%$ & \\
\hline & Stress & & & & & $100 \%$ & & & \\
\hline & Partial & & & & & & & & \\
\hline & Punctual & & & & & & & & $9 \%$ \\
\hline & Nothing & & $100 \%$ & $100 \%$ & $100 \%$ & & $100 \%$ & & $91 \%$ \\
\hline \multirow{5}{*}{$\begin{array}{l}\text { Vitry-le- } \\
\text { François }\end{array}$} & Full & $100 \%$ & & & & & & & $100 \%$ \\
\hline & Stress & & & & & & & & \\
\hline & Partial & & & $84 \%$ & & & & & \\
\hline & Punctual & & & & & & $8 \%$ & & \\
\hline & Nothing & & $100 \%$ & $16 \%$ & $100 \%$ & $100 \%$ & $92 \%$ & $100 \%$ & \\
\hline \multicolumn{2}{|c|}{ Total of marking replaced } & $48 \%$ & $9 \%$ & $12 \%$ & $20 \%$ & $39 \%$ & $1 \%$ & $86 \%$ & $19 \%$ \\
\hline
\end{tabular}

Table 1. Estimate maintenance actions on the NR4 skip center lines between 2008 and 2015.

According both to restricted data and table 1, major maintenance campaigns took place in 2008 (48\%) and 2014 (86\%).

Even if Sézanne and its neighborhood are in the same management team area, they have two different histories. The first is regularly punctually maintained (31\% in 2009, 7\% in 2011 and 4\% in 2015) and the second is fully maintained two times (2011 and 2014) and. Both benefit of a Full Maintenance in 2014. However, the second present a stressed situation.

Even if Sommesous and the Frignicourt maintenance team aren't in the same management team area, they have the same maintenance historic. However in 2008 Sommesous benefited of a partial over maintenance. This situation may be an extension of the maintenance campaign on the Frignicourt maintenance team cluster.

Our maintenance detector presents some limit.

1. A minimum of two inspections is necessary. In the NR4 case, maintenance actions in 2007 are not detectable.

2. Imperfect actions are not detectable. For example, if the "sandwich" technique (Fig 3b) is used to lay marking and the valve delivering glass beans is defective then "new" markings could be no retroreflective. 
3. More regular inspections could detect more easily premature aging situations. The current literature shows that marking admits a fast decay period during the year after its installment (Sathyanarayanan, et al., 2008) (Karwa \& Donnell, 2011) (Sarasua, et al., 2003). In addition to a strong traffic, this situation could explain why the first two clusters admit different maintenance in 2014.

In the case of no maintenance historic, our detector combined with clusters indicate main replacements. Thanks to estimate lay date, maintenance cycle can be identified. The detector shows that the AHC clusters in function to the strongest retroreflection values.

\subsection{Validation of the detector}

A marking maintenance cycle is defined by the evolution retroreflexion between its lay date and its replacement date. All cycle can be extract according to table 1 . In the NR4 case, 14 cycles is identified.

Figure 9 shows the cycle between 2008 and 2011. It represents 62 markings located both Sommesous cluster and the Frignicourt management team cluster. According to table 1 in 2008, these clusters were respectively partially (79\%) and fully maintained. Retroreflexion degradation evolves clearly on two step. The first step between 2008 and 2010 is a fast decay period: on average $-400 \mathrm{mcd} / \mathrm{m}^{2} / \mathrm{lx}$ in 2009 and $-200 \mathrm{mcd} / \mathrm{m}^{2} / \mathrm{lx}$ in 2010 . The last step shows a stable retroreflection evolution: on average +15 $\mathrm{mcd} / \mathrm{m}^{2} / \mathrm{lx}$. This pattern is according to the current literature (Sathyanarayanan, et al., 2008) (Karwa \& Donnell, 2011) (Sarasua, et al., 2003).

The detector is able to extract maintenance cycles and these cycles are according to the current literature. This result can be exploited for a next Weibull analysis.

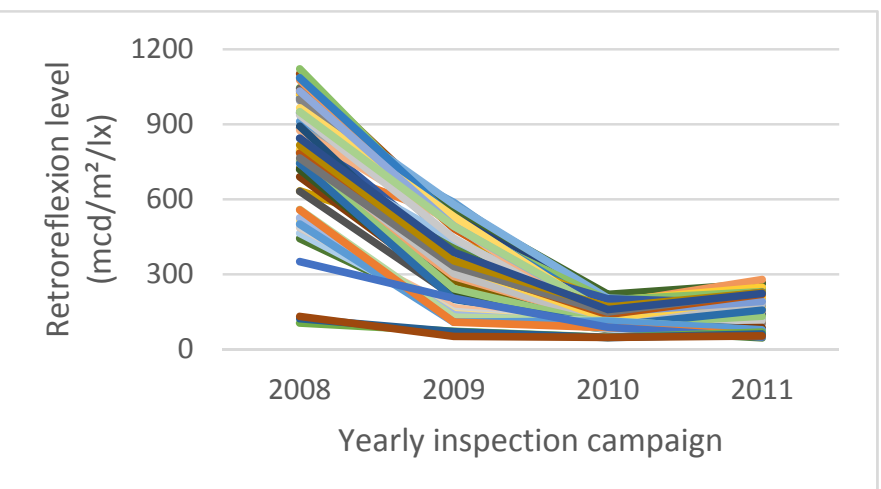

Figure 9. Maintenance cycle on the NR4 skip center lines between 2008 and 2011.

\section{CONCLUSION}

The current literature is based under some condition. For example: only a private cars trip is considered, the study starts six months after the lay date of markings or the road is monthly inspected. Our approach is more adequacy with the reality on the ground. The road is yearly inspected and there is no follow-up of the maintenance. To considerate a life analysis of marking, it's necessary to simplify the road to few strategic area and estimated main lay date of marking.

The AHC methodology is able to reduce the study to few clusters. In the case of no maintenance historic, our detector, combined with clusters, indicates main replacements. Thanks to estimate lay date, maintenance cycle can be identified. In the NR4 example, five clusters are identified. Each cluster shows strategic region and match with the current management. The maintenance detector identifies 19 replacement actions and 14 maintenance cycles. These cycles will be exploited for a next Weibull analysis.

Except the problem of no maintenance historic, the management of incomplete data isn't discuss. The AHC accepts incomplete data: it shows an extend version of current clusters. Unfortunately the detector cannot accept incomplete data because it need the evolution between two inspections. To complete data, (Sathyanarayanan, et al., 2008) purpose a linear interpolation approach. A proposition based on EM Algorithms (McLachlan \& Krishnan, 2008) is investigated. Reasons are the retroreflection evolution isn't linear (Fig. 8) and the EM approach may evaluate missing data according to current data.

\section{ACKNOWLEDGMENT}

VEDECOM and IFSTTAR thank the DIR Est and the CEREMA for inspection data on the National Road 4.

\section{REFERENCES}

AFNOR, 2009 . NF EN 1436+A1 - Road marking materials - Road marking performance for road users. Saint Denis La Plaine (France): AFNOR Editions.

Bahar, G. et al., 2006. Pavement marking materials and markers: Real-world relationship between retroreflectivity and safety over time.. NCHRP web-only Document 92 - Transportation Research Board.

Direction Interdépartementale des Routes de l'Est, 2008. La signalisation horizontale - Politique d'entratien et de renouvellement et 
recommandations pour les concepteurs routiers, Nancy: s.n.

France, V., 2017. ECODYN mlpc® - Signing visibility. [Online]

Available at: http://vectrafrance.com/materials-andsolutions/road-surface-testing/ecodyn-mlpcR-

signing-visibility? $\mathrm{L}=6$

Instruction interministérielle sur la signalisation routière, s.d. 7ème partie : Marquages sur chaussée.. Paris: Journal officiel du 12 mars 1988.

Karwa, V. \& Donnell, E., 2011. Predicting Pavement Marking Retroreflectivity Using Artificial Neural Networks Exploratory Analysis. Journal of Transportation Engineering,, 137(2), pp. 91-103.

McLachlan, G. \& Krishnan, T., 2008. The EM Algorithm and Extensions. s.l.:John Wiley \& Sons.

Migletz, J., Graham, J., Harwood, D. \& Bauer, K., 2001. Service Life of Durable Pavement Markings. Transportation Research Record, Issue 1749, pp. 13-21.

Sarasua, W., Clarke, D. \& Davis, W., 2003. Evaluation of interstate pavement marking retroreflectivity, Clemson Univ., Clemson, S.C.: Rep. No. FHWA-SC-03-01.

Sathyanarayanan, S., Shankar, V. \& Donnell, E., 2008. Pavement Marking Retroreflectivity Inspection Data - A Weibull Analysis. Transportation Research Record : Journal of the Transportation Research Board, 08(2055), p. 63-70.

Tufféry, S., 2011. Data Mining and Statistics for Decision Making. s.l.:John Wiley \& Sons.

Zhang, Y. \& Wu, D., 2006. Development of methodologies to predict service lives of pavement marking materials. Journal of the Transport Research, 45(3), pp. 5-18. 